\title{
Management, innovation capacity and fear of failure in a sample of Spanish firms
}

\begin{abstract}
The management of error is considered a source of learning and its main barrier is the fear of making mistakes or fear of failure. Fear of failure is present in all human beings and therefore influences in the activity of any organization, in its performance, in its capacity for innovation and in other related variables such as leadership and climate. Then the paper objective is to analyse through the behaviours of a sample of directors of Spanish companies the relationship among performance, fear of failure and the innovation capacity in accordance with the organizational assessment model proposed by Stuart-Kotze. The importance of this work is due to determines a new and a wider field of academic study and at the same time a lookout for managers to monitor the influence of fear of failure in their organizations
\end{abstract}

Keywords: innovation, management, fear of failure, psychological safety, trust.

\section{Introduction: Innovation, Performance, Fear of Failure and Kotze Model}

To test the causal relationships between the innovative capability of an organization, its daily performance and the influence of fear to failure, we performed a multivariate analysis of the responses of a sample of managers in completing the on line M-CPI questionnaire (Momentum Continuous Performance Indicator), developed by Stuart-Kotze, (2006) and based on the assumptions described below. The questionnaire consists of 132 items, with a Likert, (1932) response scale with 6 levels of response. (0-5).

The optimum generation capacity of change initiatives (IC) of a team depends on the contribution of both managers and employees. For this to happen, in the first phase, a manager must create a proper environment of psychological safety and trust so that the team can show their talent and creativity (Lopez et all. 2015). Thus, Stuart-Kotze calls accelerating behaviours the ones that a manager exhibits in its role of leader to stimulate his team to challenge the status quo. These behaviours build a suitable environment, implementing the necessary processes to develop talent, strategic vision or continuous improvement and reserving a place on 
the agenda to generate change initiatives. The second phase of innovation is a process where these initiatives are subsequently implemented. When an innovation is implemented recurrently it becomes reflected in the DP, and runs independently of future change initiatives. Stuart-Kotze calls sustaining behaviours to those that ensure DP. Finally, Stuart-Kotze calls blocking behaviours those that generate pressure, demotivation, discomfort, frustration or stress. Those behaviours reduce the organization efficiency, facilitating the occurrence of errors and decreasing the quality of an appropriate environment for innovation. These behaviours are behaviours derived from fear of failure (Lopez et all. 2015).

The Stuart-Kotze model identifies those three categories of behaviours described through the M-CPI questionnaire. The questionnaire consists of 132 questions and is an individual self-assessment of the accelerating, sustaining and blocking behaviours shown in the workplace. This is a forced response questionnaire according to the Likert-type format 1932, where five points mean, "totally agree" and zero means, "strongly disagree".

\section{Theoretical Approach and Assumptions}

Transformational leadership motivates to a great extend climate in the workplace Sun, (2012) stimulating employees' innovative initiatives, (Lee \& Chang, 2006), improving confidence and reducing the inherent fear that employees have of making mistakes Rego, (2007). Because the FF influences climate and climate influences innovation raises the following hypothesis. The FF must bear some relation to innovation in processes and products through climate as moderator variable. This arises the following hypothesis:

- H1. There is a positive relationship between FF and IC

Moreover, transformational leadership influences performance through climate Goleman, (2001). While transformational leadership influences the performance it hypothesized that there must be also a relationship between performance and innovation related to transformational leadership, because the climate influences the performance and innovation as well. So performance must have a relation to innovation through climate as a moderator variable. To test this approach the following hypothesis is proposed:

- H2. There is a positive relationship between DP and IC

As with the initial model both scenarios resulting set forth in Figure 1. 


\section{Methodology}

To contrast the causal relationships between daily performance DP, the influence of the behaviours associated to FF and the innovative capacity IC in an organization, it has been performed an analysis of the covariance structure of the data obtained from a sample of Spanish executives Table I, through the completion of the M-CPI questionnaire developed by Stuart-Kotze. The scope of our study is limited to the Spanish territory and with respect to the sample size, they looked for a number around 300 individuals according to exploratory factor analysis (Muthén \& Muthén, 2002). The required feature was that managers have co-workers. Regarding the degree of participation, from a sample of 350 managers contacted, a total of 286 questionnaires were suitable for the project.

\begin{tabular}{cccc} 
Table 1 & & & \\
\hline Firms & Size & Nationality & Activity \\
\hline 2 & Middle & National & Construction \\
1 & Small & National & Construction \\
2 & Small & National & Consultancy \\
1 & Middle & National & Serv. Finance services \\
1 & Large & National & Telecom services \\
3 & Large & National & Services \\
2 & Small & National & Services \\
1 & Large & Foreign Multin. & Services \\
1 & Large & Spanish Multin. & Services \\
\hline
\end{tabular}

The verification of the hypotheses for this research was carried out by structural equation modelling (SEM). For data analysis the two-step procedure recommended by (Anderson \& Gerbing, 1988) was followed. In the first stage, to assess the psychometric properties of the measurement model, we conducted a confirmatory factorial analysis (CFA) of second order to check the properties of the items and select a set of homogeneous items (Nuñez \& Rodriguez-Monroy, 2015). Secondly, the proposed structural relationships between the latent variables were added and analysed by Structural Equation System. IBM SPSS statistical software IBM SPSS-AMOS V.20 was used in both cases, using the Method of Maximum Likelihood (ML) with the statistical correction proposed by (Satorra \& Bentler, 1994).

\section{Results}

In order to verify if the sample can be considered homogeneous, statistical tests of comparison of means for independent samples (Leneve test and t-tests) were performed. As a result, the samples are statistically homogeneous for each of the constructs. So it is assumed equal variances. 
The measurement model initially proposed envisaged 132 items or behaviours: Accelerating (48) Sustaining (48), Blocking (36). Through the AFC some items with low loads or high residuals were detected so that they were eliminated, leaving finally a model consisting of 28 observable variables and 3 latent constructs. All indexes of variance of each construct exceeded the minimum acceptable value of 0.50 (Bagozzi \& Yi, 1988); (Fornell \& Larcker, 1981), so that in the first construct (innovation capacity-IC) 12 variables load, in the construct 2 (PerformanceDP) 11 variables load and lastly in the construct 3 (Fear of Error -FF 5 variables load, ( $\mathrm{p}<0.05)$. Factorial analysis of the behaviours that drive the IC shows a sample adequacy of 0,951 of KMO index Kaiser-Meyer-Olkin, considered acceptable. Similarly, the KMO of the factorial analysis of the performance-oriented behaviours is 0.927 and the one corresponding to the behaviour associated with FF is 0.8 . Also, the reliability of the constructs of the model determined by Cronbach is 0.938 for the construct IC, 0.927 , for the construct DP and 0.871 for the construct FF. The internal consistency of the constructs is proved in all cases thanks to Cronbach's alpha values, which exceed the minimum acceptable value of 0.70 (Nunnally \& Bernstein, 1994). Also, all the items that make up the factorial matrix of the constructs exceed the reference value of 0.60 (Bagozzi \& Yi, 1988). According to the above results it is possible to validate the measurement model, as the convergent validity is verified by the fact that all standardized factorial loads are significant and greater than or equal to 0.7 . And in turn, the discriminant validity is also verified because all correlations between a pair of latent variables are less than the square root of the variance extracted from the variable. See Table II.

Table 2 Scales validity by construct

\begin{tabular}{|c|c|c|}
\hline \multirow{2}{*}{ Construct } & \multirow{2}{*}{ AFC, AVE, $\square$ y \% factorial load } & Correlations \\
\hline & & IC $\quad$ DP \\
\hline $\begin{array}{l}\text { Innovation } \\
\text { Capacity IC }\end{array}$ & $\begin{array}{l}\square 2=144,050 \mathrm{df}=52 \text { RMSEA }=0.078 \mathrm{CFI}=0,96 \mathrm{TLI}=0,949 \\
\mathrm{AVE}=56,503 \square=0,938 \quad \% \text { factorial } \mathrm{load}=0,803\end{array}$ & 0,896 \\
\hline $\begin{array}{l}\text { Performance } \\
(\mathrm{DOP})(\mathrm{DORT})\end{array}$ & $\begin{array}{l}\square 2=496,555 \mathrm{df}=151 \text { RMSEA }=0,05 \mathrm{CFI}=0,960 \mathrm{TLI}=0,957 \\
\mathrm{AVE}=56,696 \mathrm{\square}=0,927=0,782\end{array}$ & $0,5730,884$ \\
\hline $\begin{array}{l}\text { Fear of Failure } \\
\text { FF }\end{array}$ & $\begin{array}{l}\square 2=8,170 \mathrm{df}=3 \text { RMSEA }=0.077 \text { CFI }=0,993 \text { TLI }=0,978 \\
\mathrm{AVE}=58,302 \square=0.871 \% \text { factorial load }=0,712\end{array}$ & $0,7290,6090,808$ \\
\hline
\end{tabular}

The exploratory factorial analysis, shows that the sample perceived DP through two constructs (Figure 1): DOP, (management oriented to planning, procedures and situational analysis, and DORT (management oriented to daily task, see (Table 3). This means that planning and task are perceived as two separated activities.

\begin{tabular}{|c|c|}
\hline Group & Behavior \\
\hline IC & I try that people be recognized by their results \\
\hline IC & I'm responsible for both good and bad team performance \\
\hline IC & I present my proposals convincingly \\
\hline
\end{tabular}




\begin{tabular}{ll}
\hline IC & I eliminate obstacles to get things done \\
IC & I always act visibly \\
IC & Once someone accepts its task responsibilities, I don't interfere \\
IC & I evaluate actions based on their long-term effects \\
IC & I listen and ask others for their opinions \\
IC & I try to identify who can count and when \\
IC & I make people be part of an integrated system \\
IC & I manage by exception, letting the system take care of the daily affairs \\
IC & I'm always willing to make hard decisions \\
FF & Sometimes I get so frustrated trying to get the goals that give up \\
FF & I express my displeasure ignoring people \\
FF & I often say to agree with a decision, when I'm not \\
FF & I get angry when I get frustrated \\
FF & I get angry with people when they make mistakes \\
DORT & I pay attention to details \\
DORT & I try to help people to understand their objectives clearly \\
DORT & I am loyal to my teammates and support them \\
DORT & I am accessible to people \\
DORT & I am patient with people when they make mistakes \\
DORT & I put the strategy in terms of goals to the team \\
DORT & I try to observe processes and procedures \\
DORT & I make sure people know exactly how it will measure its performance \\
DORT & I try the people feel at work like in family \\
DORT & I set priorities and I focus on them \\
DORT & I Develop systems and processes that deal with the daily task \\
DOP & I submit decisions to a careful analysis \\
DOP & I assess the risks carefully \\
DOP & I try people find a point of agreement in disputes \\
DOP & I keep a report on the progress of the work \\
DOP & I Attempt to solve problems by parts \\
DOP & I help people to develop their skills and trust \\
DOP & I often act as a mediator to get people to agree \\
DOP & I need hard data to make a decisions \\
DOP & I never forget deadlines \\
\hline
\end{tabular}

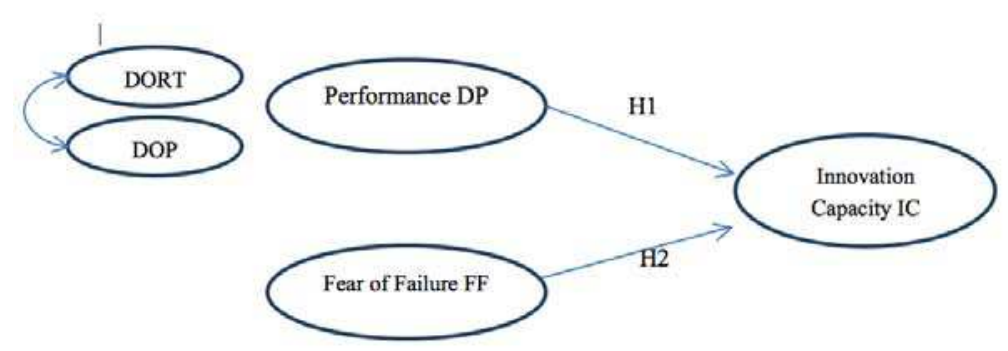

Figure 1 Initial model 
Besides, according to the resulting structural equation model, Figure 2, FF is negatively correlated with the construct DP. Also, it seems obvious that the greater the presence of FF, the less open the communication, and the greater the difficulty in learning from mistakes, which is what facilitates their repetition which negatively influences organizational efficiency. The negative correlation between FF, climate and DP is fully in line with literature on this subject. Along the same lines, SEM corroborates our first hypothesis about the causal relationship between FF and IC (see Figure 2). Finally with respect to the second hypothesis, SEM confirms the existence of a causal relationship between DP and IC.

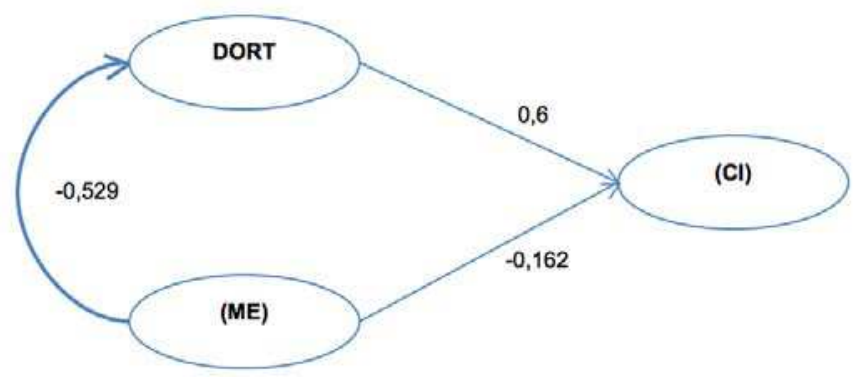

Figure 2 Final model

\section{Discussion and Conclusions}

The non-inclusion of DOP in the DP structure, leads us to consider a new hypothesis for future research. It is possible that this lack of planning in DP is the cause of management by putting out fires, something common in many Spanish companies. Since our outcomes indicate that the problem is not the lack of planning but a question of not being aware that strategic planning should be related with the daily tasks, DP. In fact, in the SEM the DOP construct is excluded from the model. May be a reason for that is the fact that in large organizations the larger the number of managers make decisions, the greater the chance for conflict. So, there is a negative interaction between planning and decentralized organizations Andersen, (2004). To explain outcomes it could be that, in order to avoid the appearance of conflicts the sample of companies under study does not pay so much attention to planning. Also, the negative correlation among FF, climate and DP is fully consistent with the literature. 
The corroboration of the first hypothesis, that is the existence of causal link between FF and DP, is consistent with the literature because of the behaviours associated with FF have a negative impact on the climate. This means a lack of transformational leadership, the leadership style that boost the climate (Sun et al. 2012) and drives innovation and change, (Lee \& Chang, 2006). With regard to the confirmation of the second hypothesis, the outcomes show that it seems that the sample accelerating behaviours tend more toward building an integrated system, with suitable processes and consistent with a strategic vision, that push teams to challenge the status quo. Although the structure of the Stuart-Kotze model has not allowed establishing any causal relationship between the action orientation in DP and the system orientation IC, it seems that the sample could be doing two things:

On the one hand, they use their accelerating behaviours, initiative, coordination and development of processes to establish, in accordance with the strategic vision, improvements in the system, integrating activities across the organization, in order to prevent errors in performing DP. This hypothesis would explain the correlation between FF and DP, where FF motivates preventing errors in order to assurance the efficiency in DP, which in turn drives IC. That is, the performance efficiency motivates change. The improvements implementation would be a responsibility delegated to employees, but without taking into account their own initiatives, because that could increase the likelihood of errors out of the management control. In this way, change is always a management decision.

However, the lack of behaviours aimed at promoting employee initiative, as a part of the set of accelerating behaviours, suggests that the purpose of the accelerating behaviours of our sample is merely to create a good climate in order to ensure efficiency in DP and even for instance to ensure the good results of the organizational climate assessment. This means that a good climate that benefits both good efficiency in DP and enables IC is only used to ensure DP, while retaining the benefit of accelerating behaviours that promote IC, as a latent potential. One possible explanation that would require further analysis is that the lack of change initiatives depends not only on the organizational climate of companies in our sample, but the allocation of time in the day-to-day running of the company, thus lacking an opportunity for the employees to express their initiatives. Furthermore, this latent potential will be even more eroded, with the passing of time, due to the employees demotivation at having been excluded from the whole innovation process.

Even though the limitation of our sample prevents us from extrapolating the outcomes to all Spanish business organizations, the outcomes are a source of information for managers who can monitor whether the presence of narcissistic behaviours are affecting their organizations. The importance of reducing the FF in managers is evident from the benefits that can result in the organizations: improving teamwork and transformational leadership, with their corresponding impact on the IC of the organizations, which is the release of innovative potential, due to the 
employees participation in the whole innovation process and besides the contribution to the daily performance, climate and error prevention management which enhances the intellectual capital of the company.

\section{References}

Andersen, T.J (2004) Integrating decentralized strategy making and strategic planning pro-cesses in Dynamic Environments. Journal of Management Studies, 41, 1271-1299.

Anderson JC, Gerbing DW (1988) Structural equation modelling in practice. A review and recommended two-step approach. Psychology Bulletin, 103, 411-4(23.

Bagozzi RP, Yi Y (1988) On the evaluation of structural equation models. Journal of the Academy of Marketing Science, 16, 74-94.

Fornell C, Larcker DF (1981) Evaluating structural equation models with unobservable variables and measurement error. Journal of Marketing Research, 18, 39-50.

Goleman DP (2001) The emotionally intelligent workplace: How to select for measure, and improve emotional intelligence in individuals, groups, and organizations. Jossey-Bass. San Francisco, CA, USA.

Lee Y, Chang, H (2006) Leadership style and innovation ability. An empirical study of Taiwanese wire and cable companies. The Journal of American Academy of Business, 9, (218(2) $2(2$.

Likert R (1932) A technique for the measurement of attitudes. Archives of Psychology, (2(2140), 1-55.

Muthén LK, Muthén BO (2002) How to use a Monte Carlo study to decide on sample size and determine power. Structural Equation Modeling, 4, 599-6(20.

Núñez Y, Rodríguez-Monroy C (2015) Gestión de recursos intangibles en instituciones de educación superior. Revista RAE 55, 65-77.

Nunnally J, Bernstein I (1994) Psychometric Theory. McGraw Hill. New York, USA.

Rego A, Sousa F, Pina M et al (2007) Leader self-reported emotional, intelligence and perceived employee creativity. An exploratory study. Creativity and Innovation Management. 16, 250264.

Satorra A, Bentler PM 1994) Corrections to test statistics and standard errors in covariance structure analysis. En Von Eye A, Clogg CC Eds.) Latent Variable Analysis. Applications for Developmental Research. Sage. Thousand Oaks, CA, USA. 399-419.

Stuart-Kotze R (2006) Performance. The Secrets of Successful Behaviour. Prentice Hall. England.

Sun W, Xu A, Shang Y (2012) Transformational leadership, team climate, and team performance within the NPD team. Evidence from China. Asia Pacific Journal Management Published on line. 